\title{
Construção de portfólios coletivos em currículos tradicionais: uma proposta inovadora de ensino-aprendizagem
}

\author{
The construction of collective portfolios in traditional curriculums: \\ an innovative approach in teaching-learning
}

\author{
Rosângela Minardi Mitre Cotta ${ }^{1}$ \\ Luciana Saraiva da Silva ${ }^{1}$ \\ Lílian Lelis Lopes ${ }^{1}$ \\ Karine de Oliveira Gomes ${ }^{2}$ \\ Fernanda Mitre Cotta ${ }^{3}$ \\ Regina Lugarinho ${ }^{4}$ \\ Sandra Minardi Mitre ${ }^{5}$
}

\footnotetext{
${ }^{1}$ Departamento de Nutrição e Saúde, Universidade Federal de Viçosa. Avenida PH Rolfs s/n Campus Universitário, Centro. 36571-000 Vicosa MG. rmmitre@ufv.br

${ }^{2}$ Instituto Multidisciplinar em Saúde, Universidade Federal da Bahia

${ }^{3}$ Faculdade de Medicina de Barbacena

${ }^{4}$ Universidade Federal do Estado do Rio de Janeiro Unirio

${ }^{5}$ Faculdade de Ciências Médicas de Minas Gerais
}

\begin{abstract}
Education to promote health has traditionally been based on knowledge transmission methodologies. However, the current scenario calls for the training of professionals with a criticalreflective profile, who are able to work in teams. We present the report of an innovative experience using the construction of collective portfolios as instruments of learning, changing attitudes and training of undergraduates, in a traditional subject-based curriculum structure context. It is a descriptive exploratory study, with a qualitativequantitative approach, based on analysis of collective portfolios $(n=9)$, built by Health Policy students, together with an open questionnaire to students who attended the course $(n=58)$ and also the staging of focus groups $(n=3)$. The use of collective portfolios mobilized students in critical and reflective thinking on Brazilian health policy the Unified Health System - broadening the concept on the health-disease process and practices related to health services, prioritizing teamwork and the active search for knowledge building, stressing the exercise of otherness, resilience and empowerment.

Key words Portfolio, Teaching-learning methodologies, Health education, Professional training
\end{abstract}

Resumo Tradicionalmente, a educação em saúde se baseia em metodologias de transmissão de conhecimentos. Porém, agora se exige a formação de profissionais com perfil crítico-reflexivo e capazes de trabalhar em equipes. O que requer novas metodologias de ensino-aprendizagem, tendo na problematização um instrumento de transformação. É relatada experiência utilizando a construção de portfólios coletivos na aprendizagem, como mudança de atitudes e na avaliação de alunos de graduação, em contexto de estrutura curricular tradicional e por disciplinas. Estudo exploratório descritivo, com abordagem quali-quantitativa, fundamentado na análise de portfólios coletivos $(n=9)$, construídos pelos acadêmicos da disciplina Politicas de Saúde, complementado com a aplicação de um questionário aberto aos alunos $(n=58)$ e com a realização de grupos focais $(n=3)$. Os portfólios coletivos mobilizaram o pensamento crítico-reflexivo sobre a política do Sistema Único de Saúde, ampliando a concepção sobre o processo saúde-doença e as práticas relacionadas aos serviços de saúde, valorizando o trabalho em equipe e a busca ativa na construção do conhecimento, destacando-se os exercícios da alteridade, resiliência e empoderamento.

Palavras-chave Portfólio, Metodologias de ensino-aprendizagem, Problematização, Educação em saúde, Formação profissional, Avaliação 


\section{Introdução}

As rápidas transformações das sociedades contemporâneas têm colocado em debate, de modo muito expressivo, os aspectos relativos à educação e à formação profissional, com destaque ao desenvolvimento de uma visão sistêmica e ecológica do homem para seu adequado desempenho laboral. Na saúde, estas transformações vêm ganhando contornos próprios quando se coloca em cheque a estrutura curricular tradicional, pobre em integrar teoria e prática, cada vez mais especializada e dissociada das preocupações sociais ${ }^{1-3}$.

Historicamente, os profissionais de saúde têm recebido uma formação baseada em metodologias de ensino aprendizagem conservadoras (tradicionais), sofrendo forte influência do mecanicismo de inspiração cartesiana-newtoniana, fragmentado e reducionista ${ }^{2,4,5}$.

Tais práticas têm restringido, muitas vezes, o processo ensino-aprendizagem à reprodução do conhecimento, no qual o educador detém o monopólio do poder, assumindo o papel de transmissor de conteúdos e formulador de questões, ao passo que, o educando precisa dar as respostas, reter e repetir conteúdos, sem a necessária crítica e reflexão imprescindíveis a uma aprendizagem significativa ${ }^{3,6,7}$.

Esta prática pedagógica se baseia na concepção "bancária", para a qual a educação é o ato de depositar, transferir e reproduzir valores e conhecimentos para seres de adaptação e ajustamento, passivos, ingênuos, acríticos e desprovidos de um poder criador mínimo ${ }^{8}$, o que representa um obstáculo para o pleno desenvolvimento dos profissionais de saúde.

Assim, Alves ${ }^{7}$ traz a tona questionamentos sobre os valores norteadores desta prática educativa, já que a essência da verdadeira atitude científica e filosófica é aprender a fazer perguntas e afirma que não dispomos de critérios para avaliar esta coisa imponderável a que se dá o nome de educação. Para o autor, o grande desafio à educação é a possibilidade de criar novos objetos de linguagem, que sejam capazes de fazer explodir a ação criativa.

Segundo a Lei $n^{\circ} .9394^{9}$, a avaliação é um processo contínuo e cumulativo do desempenho do aluno, devendo prevalecer os aspectos qualitativos sobre os quantitativos e refletir os resultados ao longo do período de estudo. De forma complementar, as Diretrizes Curriculares Nacionais para o Ensino de Graduação dos cursos da área da saúde, instituídas na resolução CNE/CES, orientam que essas avaliações deverão ser baseadas nas competências, habilidades, atitudes e conteú- dos curriculares, utilizando metodologias e critérios para o acompanhamento e avaliação do processo ensino-aprendizagem do próprio curso ${ }^{10}$.

A partir desta perspectiva, as tendências atuais na área da educação apontam para a utilização de metodologias ativas de ensino-aprendizagem, visando tornar o aluno o protagonista do seu próprio processo de formação ${ }^{11}$. Igualmente, os instrumentos de aprendizagem e avaliação devem ser capazes de desencadear uma visão do todo e ainda incentivar a construção de redes de mudanças sociais que possibilitem a expansão da consciência individual e coletiva ${ }^{3,4}$.

As metodologias ativas baseiam em estratégias de ensino fundamentadas na concepção pedagógica crítico-reflexiva, que permitem uma leitura e intervenção sobre a realidade, favorecendo a interação entre os diversos atores e valorizando a construção coletiva do conhecimento e seus diferentes saberes e cenários de aprendizagem. Além disso, são práticas que estimulam a criatividade na construção de soluções aos problemas e que promovem a liberdade no processo de pensar e de agir ${ }^{11,12}$.

Dentre as várias propostas de metodologias ativas, a problematização tem sido muito utilizada como estratégia de ensino e aprendizagem, por apresentar uma abordagem pedagógica que estimula a participação do educando, desenvolvendo a autonomia e a compreensão da responsabilidade individual e coletiva no processo de aprendizagem ${ }^{8}$.

De acordo com Alves ${ }^{7}$, quanto mais separado da existência um determinado conteúdo estiver, maiores e mais complicadas as serão mediações verbais, ao passo que, tudo aquilo que é experimentado não precisa ser ensinado e nem repetido para ser memorizado. Por conseguinte, constatando e conhecendo os problemas o educando se detém, examina, reflete, relaciona a sua história, busca ativamente conhecimentos cientificamente produzidos e passa a ressignificar suas descobertas, podendo intervir na realidade e atuar no mundo de forma significante e transformadora ${ }^{3,13-16}$.

Assim, entre os recursos inovadores do processo de ensino-aprendizagem e de avaliação, destaca-se o portfólio, como instrumento-estratégia de estimulação do pensamento reflexivo. Pois permite ao educando documentar, registrar e estruturar os processos de sua própria aprendizagem, visto que a construção se pauta na pactuação entre educador e educando ${ }^{17}$ possibilitando o trabalho colaborativo na articulação e na solução de problemas complexos ${ }^{18}$.

O portfólio também incentiva o aluno a colecionar suas reflexões e impressões sobre a disci- 
plina, opiniões, dúvidas, dificuldades, reações aos conteúdos e aos textos estudados, às técnicas de ensino, sentimentos e situações vividas nas relações interpessoais ${ }^{19}$, oferecendo subsídios para a avaliação dele, a do educador, a dos conteúdos e a das metodologias de ensino-aprendizagem, assim como para estimar o impacto da própria disciplina ${ }^{20}$.

Com base em tais considerações e ressaltando-se que as atuais políticas nacionais de saúde e educação apontam para a necessidade de mudanças nos processos de formação profissio$\mathrm{nal}^{3,21}$, fez-se a opção pela metodologia problematizadora na disciplina de Políticas de Saúde da UFV, empregando a utilização de portfólios coletivos - portfólios construídos em grupos/equipes de 6 ou 7 alunos -, como estratégia de ensino-aprendizagem e de avaliação da apropriação do conhecimento.

A proposta de construção do portfólio coletivo foi apresentada aos alunos no primeiro dia de aula, e solicitou-se que estes fizessem, em casa, uma pesquisa na literatura científica disponível sobre os diferentes conceitos e usos do portfólio, elaborando um conceito próprio a partir das leituras realizadas. $\mathrm{Na}$ semana seguinte, em sala de aula, os alunos se dividiram em grupos (de 6 ou 7 alunos), e na primeira parte da aula (primeira hora), em pequenos grupos cada um apresentou o seu conceito e as referências pesquisadas e depois de discutirem, cada grupo elaborou um conceito próprio, a partir das pesquisas individuais e discussões. Na segunda parte da aula (segunda hora), por meio de uma grande roda de conversa, cada grupo apresentou o seu conceito formulado à turma e discutiu-se sobre as potencialidades e fragilidades do instrumento. Pactuouse que este conceito faria parte do portfólio devendo ser revisitado sempre que o grupo julgasse importante. Desta forma, a busca ativa e as discussões em grupos, auxiliaram os discentes na apropriação da metodologia proposta.

Propôs-se aos grupos que organizassem o portfólio da seguinte forma: $1^{a}$ Parte: - Minha trajetória - cada um se apresenta - (quem sou eu, de onde vim, como cheguei aqui, e para onde pretendo ir); e o grupo apresenta cada um - como o grupo percebe/vê cada um; 2a Parte: - Aprendendo com a disciplina - aqui são colocadas as discussões, as resenhas, os resumos, as sínteses coletivas, as situações problemas e os relatos de práticas trabalhadas, de textos, de trabalhos e de artigos que de certa forma impactaram o grupo, enfim, as atividades realizadas na disciplina; $3^{\text {a }}$ Parte: Discutindo Políticas de Saúde por meio da criatividade - nesta parte do portfólio os alunos devem, por meio de chardes, músicas, poemas, fotos, reportagens, etc, refletir sobre as conquistas, os desafios, os obstáculos, os problemas e as soluções possíveis colocadas para a saúde nos diferentes cenários do pais e do mundo.

A interação do docente com os portfólios ocorreu durante todo o semestre letivo nas salas de aula, e mais especificamente, em três momentos distintos, em datas pactuadas com os discentes antecipadamente (após um mês de aula, no meio e no final do semestre), onde os portfólios eram avaliados de modo formativo pelo docente, discutindo e orientando os grupos.

Neste sentido, este estudo teve como objetivo avaliar a experiência inovadora de construção de portfólios coletivos como instrumento de aprendizagem e mudança de atitudes de alunos em uma estrutura curricular tradicional.

\section{Material e métodos}

\section{Descrição espaço-temporal}

Este estudo apresenta o relato de uma experiência inovadora na disciplina Políticas de Saúde da Universidade Federal de Viçosa (UFV), MG, no primeiro semestre letivo de 2008. Foi adotada como estratégia de ensino-aprendizagem a construção de portfólios coletivos conjugando estratégias de metodologias ativas-problematizadoras e métodos clássicos de avaliação, exigidos nas estruturas de currículos tradicionais. A estratégia utilizada objetivou avaliar a evolução do conhecimento dos alunos no decorrer do semestre, estimular o exercício do pensamento crítico-reflexivo, a autonomia e a responsabilização na busca ativa de informações tanto na literatura científica quanto na mídia e exercitar o trabalho em equipe.

Esta disciplina compõe um dos conteúdos essenciais para a formação profissional na área de Saúde Pública, pois trabalha questões relevantes e abrangentes sobre as políticas de saúde no Brasil e no mundo, tais como o processo histórico de formação das políticas sociais e de saúde, os diferentes paradigmas sanitários, os determinantes estruturais, econômicos, políticos e sociais que repercutem sobre o processo saúdedoença, bem como suas implicações para a prática profissional.

\section{Desenho do estudo}

Trata-se de um estudo exploratório descritivo, de abordagem quali-quantitativa, fundamentado na análise de portfólios coletivos ( $\mathrm{n}=$ 
9), construídos pelos acadêmicos da disciplina Políticas de Saúde, e complementado com a aplicação de um questionário aberto aos alunos que cursaram a referida disciplina $(n=58)$ e realização de grupos focais $(n=3)$.

O questionário (Quadro 1) abordou temas referentes aos tipos de metodologias de ensino adotados na disciplina, buscando identificar as opiniões, apreensões, percepções e preferências dos alunos sobre o processo ensino-aprendizagem - se baseado em metodologias ativas ou tradicionais.

Por fim, os grupos focais foram realizados para verificar a percepção dos alunos em relação à utilização do portfólio coletivo como instrumento de ensino-aprendizagem e de avaliação do conhecimento para além do desenho tradicional de ensinar e aprender.

\section{Análise dos dados}

Os portfólios foram construídos ao longo do semestre letivo, sendo que a avaliação e a apreciação destes se deram em três momentos distintos durante o semestre.

A aplicação dos questionários e os grupos focais ocorreram no final do semestre letivo.

Após leitura global e exaustiva das respostas dos alunos aos questionários, foi realizada a análise de conteúdo cumprindo três etapas: (1) Préanálise, (2) Exploração do material e (3) Tratamento dos resultados, inferência e interpretação ${ }^{22,23}$, o que permitiu identificar os núcleos de sentido e organizar as categorias sobre a utilização da metodologia ativa como forma de ensino, aprendizado e avaliação.

Em relação aos grupos focais estes foram coordenados pela professora da disciplina e os depoimentos dos alunos foram anotados por dois facilitadores, e posteriormente foram analisados exaustivamente.

De forma complementar, mas não menos importante, confrontou-se as análises dos grupos focais e dos questionários com os depoimentos, relatos e documentos que compunham os portfólios.

Os dados quantitativos foram analisados através do cálculo da frequência das variáveis, tendo em vista a própria natureza descritivo-exploratória do estudo.

\section{Resultados e discussão}

\section{Avaliação do portfólio enquanto estratégia de ensino-aprendizagem e de avaliação: percepções positivas e negativas relatadas pelos alunos}

Após a análise dos portfólios e a leitura exaustiva, tanto das respostas dos questionários quanto dos relatos apresentados nos grupos focais, foi possível examinar detalhadamente (desmembrar) as significações mais evidentes e representativas apontadas pelos alunos em relação à utilização do portfólio como instrumento de ensino, aprendizagem e avaliação. Além disso, os atrativos semânticos extraídos das respostas dos alunos permitiram a articulação desse conjunto como um sistema de indicadores sobre a utilização do portfólio e da metodologia ativa na disciplina Políticas de Saúde.

Segundo Conde e Marinas ${ }^{24}$, o conjunto de respostas tende a condensar-se, em uma série de termos, expressões e imagens que exercem uma

Quadro 1. Questões norteadoras para a avaliação da experiência vivenciada pelos alunos na construção de portfólios coletivos. Universidade Federal de Viçosa, MG, Brasil, 2008.

\begin{tabular}{|l|l|}
\hline Questão 1 & $\begin{array}{l}\text { Como você avalia a utilização do portfólio como instrumento de aprendizagem e avaliação? } \\
\text { Destaque os pontos positivos (pontos fortes), os negativos (fragilidades do instrumento) } \\
\text { e os obstáculos enfrentados, enfatizando as estratégias utilizadas para superá-los. }\end{array}$ \\
\hline Questão 2 & $\begin{array}{l}\text { Se você pudesse escolher entre a metodologia tradicional e a metodologia ativa } \\
\text { (problematização) como instrumento de aprendizagem, que metodologia você elegeria? } \\
\text { Reflita sobre sua resposta. }\end{array}$ \\
\hline Questão 3 & $\begin{array}{l}\text { Quais as principais mudanças (caso tenham ocorrido) você aponta como importantes para } \\
\text { sua vida profissional e/ou cidadã acarretadas pelo processo de aprendizagem advindos da } \\
\text { disciplina de Políticas de Saúde? }\end{array}$ \\
\hline Questão 4 & $\begin{array}{l}\text { Que habilidades você acredita ter adquirido/exercitado a partir da metodologia participativa } \\
\text { e construção de portfólios coletivos utilizada na disciplina? }\end{array}$ \\
\hline Questão 5 & \begin{tabular}{l} 
Defina em uma frase o sentimento/sensação experimentado por você ao final da disciplina. \\
\hline
\end{tabular}
\end{tabular}


função de "atrativos semânticos", de modo que em torno de cada termo se situa um conjunto de palavras, expressões chaves significativas das situações e concepções próprias de cada grupo, como é o caso dos alunos entrevistados.

A maioria dos alunos $(57,1 \%)$ avaliou positivamente a experiência de utilização do portfólio como instrumento de ensino-aprendizagem e de avaliação, enquanto $41,1 \%$ apontou alguns pontos negativos e apenas $1,8 \%$ não relatou não ter encontrado nenhuma dificuldade na utilização deste instrumento.

As Tabelas 1 e 2 apresentam os atrativos semânticos positivos e negativos sobre a utilização do portfólio como estratégia de aprendizagem na disciplina Políticas de Saúde.
Em relação aos pontos positivos do portfólio, foram destacadas a capacidade que o instrumento possui para reforçar, avaliar e ampliar o conhecimento, uma vez que permite a revisão contínua e um maior envolvimento dos alunos com os conteúdos trabalhados. Além disso, o portfólio estimula a associação dos assuntos abordados na disciplina tanto com o mundo real como com a vida dos alunos, através da associação dos conteúdos com reportagens, músicas, charges, filmes, poesias, entre outros recursos que despertam o interesse pelo estudo, conforme se ilustra pelo depoimento que se segue:

"O portfólio é um bom método, nos ensina a refletir sobre o conteúdo dado em sala de aula, e nos instiga a ir além do conteúdo, buscando in-

Tabela 1. Atrativos semânticos positivos sobre a utilização do portfólio como estratégia de aprendizagem na disciplina Políticas de Saúde. Universidade Federal de Viçosa, MG, Brasil, 2008.

\begin{tabular}{lrr}
\hline \multicolumn{1}{c}{ Percepções Positivas } & $\mathbf{n}^{*}$ & $\%$ \\
\hline Reforça o aprendizado: & 53 & 100 \\
1. Amplia o conhecimento/aprendizado & 32 & 60,4 \\
2. Boa ferramenta de aprendizagem/avaliação & 13 & 24,5 \\
3. Propicia a revisão e um maior envolvimento com as temáticas tratadas & 1 & 1,9 \\
4. Relaciona conteúdo com cotidiano/atualidade (artigos, músicas, filmes, reportagens) & 7 & 13,2 \\
Estimula o trabalho em equipe: & 19 & 100 \\
1. Melhora a convivência entre os membros do grupo/dinâmica/trabalho; propicia a & \\
aproximação com os colegas de curso; favorece a amizade. & 11 & 100 \\
Liberdade de expressão: & 8 & 72,7 \\
1. Permite a demonstração de opiniões/idéias, ajuda na verbalização e discussão sobre os & 3 \\
momentos bons e ruins & 27,3 \\
2. Foge ao padrão de prova, não precisa decorar, estimula o pensar & 17 & 100 \\
Desenvolvimento de habilidades pessoais: & 7 & 41,2 \\
1. Desenvolve o pensamento crítico-reflexivo & 6 & 35,3 \\
2. Exige criatividade & 3 & 17,6 \\
3. Propicia o crescimento pessoal & 1 & 5,9
\end{tabular}

"Os relatos excedem o número da amostra devido ao fato dos alunos terem mencionado mais de uma percepção sobre a utilização do portfólio.

Tabela 2. Atrativos semânticos negativos sobre a utilização do portfólio como estratégia de aprendizagem na disciplina Políticas de Saúde. Universidade Federal de Viçosa, MG, Brasil, 2008.

\begin{tabular}{lcc}
\hline \multicolumn{1}{c}{ Percepções Negativas } & $\mathbf{n}^{*}$ & $\%$ \\
\hline Conflitos: & 44 & 62 \\
$\quad$ Dificuldade de reunir (entrar em consenso com o grupo em relação a idéias, horários) & & 8,4 \\
Não contribui com o aprendizado:Não é uma boa forma de avaliar o aprendizado & 6 & 7 \\
Falta de experiência prévia com a metodologia: & 5 & 16 \\
$\quad$ Tempo gasto pela dificuldade de entender como se constrói um portfólio & 22,5 \\
Instrumento Trabalhoso: & \\
$\quad$ Bastante trabalhoso & \\
\hline
\end{tabular}

* Os relatos excedem o número da amostra devido ao fato dos alunos terem mencionado mais de uma percepção sobre a utilização do portfólio. 
formações em outras fontes, nos faz rever nossos erros a serem corrigidos e abre o mundo a novas possibilidades."

Para Coll ${ }^{25}$, uma das características mais importantes da metodologia ativa é a sua capacidade de despertar nos alunos a aptidão para relacionar o aprendizado anterior ao novo, o que não ocorre na abordagem mecânica tradicional. De acordo com este autor, a aprendizagem só acontece quando existe um conteúdo potencialmente significativo, acompanhado de uma atitude favorável, ou seja, quando o aluno estabelece associações entre os elementos novos e aqueles já presentes na sua estrutura cognitiva.

Outro ponto positivo reforçado pelos alunos sobre o uso do portfólio foi o estímulo ao trabalho em equipe, oferecendo a oportunidade de estreitamento, da formação de vínculo e da amizade entre os membros do grupo, além de aumentar a integração, melhorar a convivência e favorecer a aprendizagem de todos os integrantes, por meio das discussões, reflexões e troca de ideias realizadas sobre os conteúdos trabalhados na disciplina.

"O portfólio contribuiu positivamente para o aprendizado, pois promoveu uma integração entre os membros do grupo, gerando troca de ideias, discussões e reflexões críticas acerca dos temas abordados na disciplina."

A riqueza das diferenças é considerada uma contribuição fundamental para o trabalho em equipe, pois as opiniões distintas e baseadas em diferentes experiências, formações e pontos de vista levam a um resultado mais qualificado e significativo para cada um, individualmente e para o grupo como um todo ${ }^{4,13}$.

Por fim, a liberdade de expressão e o desenvolvimento de habilidades pessoais foram fatores que também influenciaram na avaliação positiva do portfólio por parte dos alunos.

"O portfólio é um bom instrumento sim. Permite que o grupo expresse suas ideias, de forma espontânea sem juízo de valor - não existe certo ou errado, apenas pontos de vistas, e não temos oportunidade de fazer este exercício nas disciplinas tradicionais."

O portfolio permitiu também que os alunos participassem ativamente do processo ensinoaprendizagem e alcançassem um crescimento para além da sala de aula e do conteúdo programático da disciplina, conforme ilustra o depoimento abaixo:

"Estimula a criatividade e a constante busca de atualizações, o grupo aprende a se comunicar tanto por meio da linguagem técnica como por meio de expressões criativas, tais como, poesias, músicas, fotos, charges...."
Os achados de nosso estudo vai ao encontro dos de Villas Boas ${ }^{19}$, que ressalta que "o portafólio é um instrumento riquíssimo e que garante a beleza da construção própria, individual, personalizada. Costumo dizer que é um momento de duplo prazer no processo educacional: você como autor/produtor de sua vivência e ao mesmo tempo leitor de sua obra, de sua prática, de sua atuação pedagógica. Autor e leitor de si mesmo!"

Não obstante, entre os relatos de avaliação negativa do portfólio, destacaram-se os conflitos vivenciados durante sua construção, principalmente por causa da dificuldade de encontrar horários comuns a todos os componentes do grupo para realizar as reuniões e pelo fato de que os alunos estavam cursando várias disciplinas ministradas nos moldes tradicionais, demandando muito tempo e dedicação.

"... como muitas coisas foram feitas em grupo, foi muito difícil chegarmos a um consenso (...). Além disso, o tempo foi muito curto, pois são inúmeras disciplinas e precisamos nos dedicar a todas."

O exercício da capacidade criadora, juntamente com a necessidade de dedicação de tempo para a elaboração do portfólio foram outros pontos negativos relatados por alguns alunos, o que os levaram a optar pela metodologia tradicional.

"Não acredito que o portfólio seja uma boa forma de avaliar nossa aprendizagem. Ele requer muito trabalho e dedicação quanto a questões de criatividade que não trazem aprendizagem."

Finalmente, a ausência de experiência prévia com a metodologia ativa foi, igualmente, apresentada como um ponto negativo sobre a utilização do portfólio.

"A maior dificuldade foi entender, inicialmente, o que seria o portfólio (o que ele deveria conter, como deveria ser organizado, não estamos acostumados a ter que pensar e criar)...”

Os aspectos negativos relatados pelos alunos nesta experiência também foram verificados por Araújo e Moraes Júnior ${ }^{26}$ e Sordi e Sampaio ${ }^{27}$.

No entanto, ainda que esta experiência tenha sido apontada por alguns alunos como muito trabalhosa, é possível concluir, mediante os conjuntos de concepções destacados pela vivência dos acadêmicos na disciplina, que a metodologia ativa contribuiu, substancialmente, para o desenvolvimento dos alunos, principalmente no que se refere à autonomia, criatividade, capacidade de organização, exercício do trabalho em equipe e participação ativa.

Ademais, o desenvolvimento e exercício destes valores nos acadêmicos representa um resultado bastante importante, uma vez que ao assu- 
mir um papel cada vez mais ativo o aluno descondiciona-se da atitude de mero receptor de conteúdos e busca efetivamente conhecimentos relevantes sobre os problemas e os objetivos da aprendizagem, capacitando-se para um exercício profissional mais autônomo ${ }^{28,29}$.

Como forma de ilustração do crescimento, do envolvimento e da aproximação dos alunos com a metodologia inovadora proposta, destaca-se a personalização criativa dos grupos, ao escolherem nomes interessantes e elucidativos para as equipes e seus portfolios, tais como "os aSUStados"; "as DEScentralizadas", "InterAGIR", "SUStentação", ResSUScitando" e "Politicando", que expressam as vivências dos alunos, tanto positivas quanto de angústias e de "medos" perante o desafio de enfrentar o novo.

\section{Metodologia tradicional \\ "versus" metodologia ativa: (re)pensando paradigmas}

Quando questionados sobre que metodologia preferiam como instrumento de aprendizagem, $79,3 \%$ dos entrevistados optaram pelo uso da metodologia ativa e apenas $12,1 \%$ optaram pela metodologia tradicional (Tabela 3), resultado que também foi encontrado por Araújo e Moraes Júnior ${ }^{26}$.

As principais justificativas dos alunos que preferiram a metodologia ativa foram de que este tipo de abordagem contribui para a sedimentação do aprendizado e estimula o pensamento crítico-reflexivo, gerando um conhecimento mais dinâmico, em função da possibilidade de interação entre a teoria abordada na disciplina com a experiência prática e a busca ativa de estudos, relatos e vivências. Além disso, a metodologia ativa facilita o aprendizado, rompendo com a forma mecânica de decorar e reproduzir os conteúdos, como reforçam os depoimentos que se seguem:

"Embora tenha parecido um pouco mais trabalhosa, tal metodologia é instigante; incentiva o aluno a buscar, aprender sempre mais e a estar sempre ligando um aprendizado ao outro, formando uma sequência lógica. Ela vem combater o 'aprendizado decorado' que, a longo prazo, em nada contribui para a formação do indivíduo enquanto profissional e ser humano."

"Desenvolve e estimula sempre a participação dos alunos. (...). Os alunos deixam de ser apenas uma figura passiva, receptor de informações, e passam a ser indivíduos mais críticos, impulsiona à reflexão/ação."

Este resultado também foi encontrado por Pernigotti e Saenger ${ }^{30}$, cuja experiência apontou as vantagens deste método de avaliação quando comparado às provas de fim de curso, revelando-se como um importante instrumento para desenvolver a capacidade de reflexão, tão pouco enfatizada nas práticas tradicionais.

Por outro lado, os alunos que escolheram a metodologia tradicional afirmaram que estavam acostumados com a metodologia e que para eles os estudantes só estudam quando são cobrados por meio de avaliações escritas. Justificaram, ainda, a dificuldade de adaptação com a metodologia ativa por esta ser bem mais trabalhosa que a tradicional.

"A metodologia ativa pode até ser válida, mas infelizmente é muito trabalhosa. E, infelizmente, o aluno só estuda de forma mais efetiva quando tem prova".

Contudo, alguns alunos optaram pela combinação das duas metodologias como a melhor forma de avaliação, visto que cada método tem seus pontos fortes e fracos, e um complementa o outro.

"Nenhuma (metodologia) é totalmente eficaz e a metodologia da problematização, muitas vezes é vista como melhor, mas demanda um tem-

Tabela 3. Atrativos semânticos sobre a preferência dos alunos em relação ao tipo de metodologia de ensino-aprendizagem na disciplina Políticas de Saúde. Universidade Federal de Viçosa, MG, Brasil, 2008.

\begin{tabular}{|c|c|c|c|c|c|}
\hline Metodologia Ativa & $\mathbf{n}^{*}$ & $\%$ & Metodologia Tradicional & $\mathbf{n}^{*}$ & $\%$ \\
\hline 1. Sedimenta o aprendizado & 30 & 38 & 1. Metodologia ativa é muito & 6 & 60 \\
\hline 2. Estimula o pensamento crítico, reflexivo & 19 & 24,1 & trabalhosa & & 10 \\
\hline e criativo & & & 2. Dificuldade de adaptar à & 1 & 30 \\
\hline 3. Permite e valoriza a participação do aluno & 18 & 22,8 & metodologia ativa & & \\
\hline 4. Vincula teoria à prática & 8 & 10,1 & 3. Costume com a metodologia & 3 & \\
\hline 5. Exige mais tempo e dedicação & 4 & 5 & tradicional & & \\
\hline
\end{tabular}

* Os relatos excedem o número da amostra devido ao fato dos alunos terem mencionado mais de uma percepção sobre a utilização do portfólio. 
po muito grande do aluno e penso que só é viável quando há uma boa base teórica - que é melhor fundamentada na metodologia tradicional."

\section{Mudanças vivenciadas e habilidades adquiridas pelos alunos com a utilização de metodologias ativas}

Para 98\% dos alunos a metodologia ativa contribuiu com algum tipo de mudança em sua vida acadêmica e cidadã, especialmente em relação à valorização do sistema de saúde brasileiro. Por sua vez, 70,2\% dos alunos, destacaram que a construção do portfolio permitiu a conscientização dos princípios e diretrizes do SUS e o aprendizado crítico da história da política de saúde do Brasil.

"Tomei consciência da realidade de saúde da população, passei a admirar o SUS ao invés de rejeitar preconceituosamente, como fazia antes... Até me motivei a trabalhar na área de saúde pública."

O exercício crítico e reflexivo sobre o processo saúde-doença, os determinantes sociais da saúde e o sistema de saúde brasileiro - SUS, foi uma das habilidades desenvolvidas pelos alunos, que informaram ter adquirido maior capacidade para análise e discussão. A maioria dos alunos passou de uma atitude passiva e negativa sobre o SUS, anterior à disciplina, para uma atitude ativa, crítica e reflexiva, informando sentirem-se mais preparados para discutir e buscar subsídios e informações a partir de novas perspectivas e olhares derivados de buscas na literatura cientifica, mídia e depoimentos de especialistas.

"Falar sobre o SUS há alguns meses atrás seria muito mais fácil do que agora. $\mathrm{O}$ meu comentário seria que o SUS é ruim. Mas isto era normal, porque tudo que é público é ruim, assim como a escola, o transporte e os demais serviços públicos. O bom é aquilo que a gente paga pra ter. Em se tratando de saúde, o bom mesmo é ter um convênio. Em apenas tão pouco tempo de estudo sobre essa nova proposta de se lidar com a saúde, já pude ver sob outra lógica os mesmos atendimentos que julgava ruins. Dentro de uma proposta de aprendizado contínuo, o conhecimento sobre essa nova abordagem em saúde continuará possibilitando maiores reflexões e, consequentemente, maior revisão de conceitos sobre o SUS e sobre vários aspectos do nosso cotidiano, e isto só foi possível porque montamos o portfolio."

Outra mudança vivenciada pelos alunos e que merece destaque foi o desenvolvimento da capacidade de trabalhar em equipe, que, embora tenha sido citada muitas vezes como um dos pontos mais desafiadores da metodologia ativa, foi percebida enquanto habilidade adquirida ao final da discipli- na. Muitos alunos conquistaram a capacidade de lidar com as diferenças existentes no grupo, exercitaram o dom da paciência, alteridade e compaixão para com os colegas e desenvolveram o interesse de interagir com a comunidade, alguns até se sentiram estimulados a participar mais ativamente das aulas e melhoraram sua capacidade de síntese.

"Ajudou na construção de uma nova visão a respeito da saúde pública e privada no Brasil. Além, é claro, da 'terapia' que é trabalhar em grupo, respeitando as opiniões, diferenças e ideias das pessoas do grupo."

"Exercitei a minha capacidade de comunicar com os colegas de trabalho e adquiri interesse em aprofundar nos assuntos que envolvem a comunidade, na interação entre profissionais de saúde e população."

"Habilidades de ter mais tranquilidade, mais responsabilidade, mais paciência e respeito pela opinião dos outros, mais competência e mais iniciativa para realizar as minhas coisas."

Finalmente, os alunos também desenvolveram uma visão mais humanizada sobre a saúde e a vida, exercitando e/ou incorporando dimensões importantes como a alteridade, a compaixão, o empoderamento e a resiliência, avaliando com muita satisfação a superação das dificuldades que encontraram durante o semestre.

"Nada muda se você não mudar, cada um é importante para o sucesso de todos."

Resultados semelhantes foram verificados por Villas Boas ${ }^{19}$, uma vez que seus alunos apresentaram uma mudança de comportamento a partir do estudo e maior intimidade com a metodologia ativa, demonstrando atitudes positivas quanto ao novo procedimento avaliativo, tais como curiosidade, admiração, alegria, paixão, orgulho pelo que conseguiu produzir, aceitação, tranquilidade, sentimento de felicidade em realizar e em divulgar seus trabalhos.

\section{Sentimentos experimentados pelos alunos ao final da disciplina}

Em relação aos sentimentos experimentados ao final da disciplina de Políticas de Saúde, 86,2\% dos alunos expressaram sensações positivas e $13,8 \%$ sensações negativas.

A principal sensação positiva relatada foi a satisfação pelo cumprimento das tarefas e a superação dos obstáculos através do esforço, da responsabilidade e da perseverança durante todo o processo de aprendizagem, como ilustra o depoimento que segue:

"Conhecimento não ocupa lugar, só nos faz crescer e aprender que tudo na vida deve ser con- 
quistado com esforço e perseverança, aprendemos isto construindo o portfólio e nas avaliações deste ao longo do semestre."

Também o exercício da responsabilidade, como futuro profissional de saúde e cidadão, com o desenvolvimento e a qualificação do SUS e do Programa de Saúde da Família (PSF), que até então eram desconhecidos pelos alunos, foi apontado nos depoimentos, como conquista e valor adquiridos no decorrer do semestre letivo e propiciado pela metodologia ativa.

"Há uma vitória a se conquistar na saúde pública do Brasil, e depois do que aprendemos nesta disciplina, estamos aptos a lutar pela correção dos erros e pela inserção das práticas corretas, a divulgar o SUS, o PSF e suas diretrizes, e tentar fazer com que todos (profissionais, usuários e gestores do SUS) tenham a visão de que saúde é um bem comum e deve ser direito de todos e bem executada: tratar, curar e prevenir o ser humano como todo."

Moulin ${ }^{17}$ também observou uma avaliação positiva, ao final de sua disciplina, sobre a experiência vivenciada com a nova técnica de avaliação, sintetizada assim por uma de suas alunas: "o portfólio é um verdadeiro veículo de integração entre o aluno e o professor".

Quanto ao conjunto de sensações negativas apontadas por alguns alunos, estas foram associadas principalmente ao sentimento de cansaço experimentado ao final de um semestre letivo marcado pela sobrecarga de disciplinas e atividades, que na maioria das vezes, seguiam o modelo tradicional.

\section{Considerações Finais}

As transformações vivenciadas pelas universidades colocam em evidência uma série de perspectivas que estimulam a compreensão histórica e crítica de suas manifestações no âmbito político. Todavia, a educação superior ainda prioriza práticas pedagógicas que, muitas vezes, não contribuem para o desenvolvimento de uma sociedade de sujeitos construtores de sua própria história.

Destarte, as concepções tradicionais de ensinar e aprender estão em constante tensão com a necessidade da introdução, nos espaços acadêmicos, de ferramentas que estimulem o desenvolvimento da consciência crítica e comprometida sobre a realidade pela comunidade acadêmica. $\mathrm{O}$ que aponta para a necessidade de introduzir experiências de aprendizagem que afora a instrução informativa e técnica, sejam capazes de reinventar o ensinar e o aprender, além de permitir a construção personalizada do conhecimento.

Os resultados deste estudo demonstraram a eficiência do portfólio coletivo como uma ferramenta estratégica na construção do conhecimento dialógico, abrindo possibilidades a uma relação dialética entre aluno-professor e universidadeserviço-comunidade. Ademais, o portfólio contribuiu com o desenvolvimento de habilidades pessoais como alteridade, resiliência e empoderamento, estimulando o trabalho em equipe e a capacidade de pactuação.

Diante disso, a utilização do portfólio coletivo, em contextos universitários orientados por currículos tradicionais, onde se trabalha com um grande número de alunos em disciplinas compartimentalizadas, surge como uma possibilidade inovadora de ensino-aprendizagem e avaliação ativa e participativa.

O papel ativo e comprometido da pesquisa individual e em grupo, inerentes à construção dos portfólios, estimula nos acadêmicos o exercício crítico-reflexivo sobre a realidade concreta que a prática sanitária se apresenta nos serviços de saúde e nas comunidades, além de estimular o trabalho em equipe e o exercício da criatividade, convivência, tolerância e compaixão, habilidades importantes para o exercício profissional e cidadão.

Por outro lado, os aspectos limitantes apresentados por alguns alunos, tais como a inexperiência prévia com o uso deste instrumento, a dificuldade para trabalhar em equipe e a capacidade criadora reprimida, demonstram a importância da utilização da metodologia ativa para o pleno desenvolvimento dos próprios alunos enquanto futuros profissionais de saúde, visto que as limitações vivenciadas são exatamente as habilidades mais exigidas no mundo de trabalho moderno.

\section{Colaboradores}

RMM Cotta, LS Silva, LL Lopes, KO Gomes, FM Cotta, R Lugarinho e SM Mitre participaram igualmente de todas as etapas de elaboração do artigo.

\section{Agradecimento}

À Capes (Coordenação de Aperfeiçoamento de Pessoal de Nível Superior), entidade do governo brasileiro voltada para a formação de recursos humanos. 


\section{Referências}

1. Capra F. A teia da vida: uma nova compreensão científica dos sistemas vivos. 6. ${ }^{\mathrm{a}}$ ed. São Paulo: Cultrix; 2001.

2. Capra F. O ponto de mutação: a ciência, a sociedade e a cultura emergente. São Paulo: Cultrix; 2006.

3. Mitre SM, Siqueira-Batista R, Giardi-de-Mendonça JM, Morais-Pinto NM, Meirelle CAB, PortoPinto C, Moreira T, Hoffmann LMA. Metodologias ativas de ensino-aprendizagem na formação profissional em saúde: debates atuais. Cien Saude Colet 2008; 13(Supl. 2):2133-2144.

4. Cotta RMM, Azeredo CM, Schott M, Martins PC, Franceschini SCC, Priore SE. Sobre o conhecimento e a consciência sanitária brasileira: o papel estratégico dos profissionais e usuários no sistema sanitário. Rev Médica Minas Gerais 2006; 16(1):2-8.

5. Cotta RMM, Gomes AP, Maia TM, Magalhães KA Marques ES, Siqueira-Batista R. Pobreza, injustiça e desigualdade social: repensando a formação de profissionais de saúde. Rev Bras de Educação Médica 2007; 31(3):278-286.

6. Behrens MA. O paradigma emergente e a prática pedagógica. Petrópolis: Vozes; 2005.

7. Alves R. Conversas com quem gosta de ensinar. $6^{\mathrm{a}}$ ed São Paulo: Papirus; 2003.

8. Freire P. Pedagogia do oprimido. Rio de Janeiro: Paz e Terra; 1987.

9. Brasil. Ministério da Educação. Lei n. 9.394, de 20 de dezembro de 1996. Estabelece as Diretrizes e Bases da Educação Nacional. Brasil. Diário Oficial da União 1996; 20 dez.

10. Brasil. Ministério da Educação. Conselho Nacional de Educação. Câmara de Educação Superior. Resolução CNE/CES no 5, de 7 de novembro de 2001 Institui Diretrizes Curriculares Nacionais do curso de graduação em Nutrição. [Documento da Internet]. [acesso 2012 fev 29]. [cerca de 5 p.]. Disponível em: http://www.ufv.br/seg/diretrizes/nut.pdf

11. Silveira RP, Dohms MC. A Medicina de Família e Comunidade e o ensino de graduação em medicina. Metodologias ativas de Ensino/Aprendizagem. Rev Bras Med Fam e Com 2006; (Supl. 1):21-25.

12. Feuerwerker LCM, Sena RR. A contribuição ao movimento de mudança na formação profissional em saúde: uma avaliação das experiências UNI. Interface Comun Saúde Educ 2002; 6(10):37-50.

13. Ferreira MLSM, Cotta RMM, Oliveira MS. Reconstrução Teórica do Cuidado para as Práticas de Saúde: Um Olhar a Partir da Produção de Alunos de Curso de Especialização a Distância. Rev Bras de Educação Médica 2008; 32(3):291-300.

14. Cyrino EG, Toralles-Pereira ML. Trabalhando com estratégias de ensino-aprendizado por descoberta na área da saúde: a problematização e a aprendizagem baseada em problemas. Cad Saude Publica 2004; 20(3):780-788.

15. Zanotto M, Rose T. Problematizar a Própria Realidade: análise de uma experiência de formação contínua. Rev Educação e Pesquisa 2003; 29(1):45-54.
16. Freire P. Ação cultural para a liberdade e outros escritos. 10a ed. São Paulo: Paz e Terra; 2002.

17. Moulin N. Utilização do Portfólio na Avaliação do Ensino a Distância. In: VIII Congresso Internacional de Educação à Distância; 2001; Brasília.

18. Murphy S. Teachers and students: reclaiming assessment via portfolios. In: Yancey KB, Weiser I, organizadores. Situating portfolios: four perspectives. Logan: Utah State University Press; 1997. p. 72-88.

19. Villas Boas BMF. O portfólio no curso de pedagogia: ampliando o diálogo entre professor e aluno. Educ Soc 2005; 26(90):291-306

20. Rosário ELSP, Barbosa EGR. O portfólio: Uma abordagem Avaliativa. Rev Interação 2002; 6(6).

21. Pedroso MB, Cunha MI. Vivendo a inovação: as experiências no curso de nutrição. Interface Comun Saúde Educ 2008; 12(24):141-152.

22. Bardin L. Análise de Conteúdo. Lisboa: Edições 70; 2008.

23. Minayo MCS. O desafio do conhecimento: pesquisa qualitativa em saúde. $10^{\text {a }}$ ed. São Paulo, Rio de Janeiro: Hucitec, Abrasco; 2007.

24. Conde F, Marinas JM. Las representaciones sociales sobre la salud de los mayores madrileños. Madrid: Consejería de Sanidad y Servicios Madrileños; 1997.

25. Coll C. Psicologia e Currículo: uma aproximação psicopedagógica a elaboração do currículo escolar. São Paulo: Ática; 2000.

26. Araújo AO, Moraes Júnior VF. Avaliação de Aprendizagem: Uma Experiência do Uso do Portfólio em um Curso de Ciências Contábeis. In: $18^{\circ}$ Congresso Brasileiro de Contabilidade; 2008; Gramado.

27. Sordi MRL, Sampaio SF. O portfólio como recurso formativo e de avaliação e seu potencial emancipatório: novos olhares, novos sentidos pedagógicos. In: IV Congresso Internacional Docencia Universitaria e Invación; 2006; Barcelona.

28. Santos SS. A integração do ciclo básico com o profissional no Curso de Graduação em Medicina: uma resistência exemplar. Rio de Janeiro, Teresópolis: Papel \& Virtual, Feso; 2005.

29. Komatzu RS, Zanolli M, Lima VV. Aprendizagem baseada em problemas. In: Marcondes E, Gonçalves E, organizadores. Educação Médica. São Paulo: Sarvier; 1998. p. 223-237.

30. Pernigotti J, Saenger L. O portfólio pode muito mais do que uma prova. Rev Pátio 2000; 3(12):54-56.

Apresentado em 11/04/2010

Aprovado em 19/06/2010

Versão final apresentada em 01/07/2010 